- Waldir Cunha Júnior

Wagner Kuriki

- Adilson Hamaii

- Beatriz G. Miron

\section{Falha no uso do estimulador de nervo periférico no bloqueio interescalênico}

\author{
Instituto de Ortopedia e Traumatologia do Hospital das Clinicas, \\ Faculdade de Medicina da Universidade de São Paulo, São Paulo
}

INTRRDUCॄÃa

A técnica de anestesia regional periférica com o uso de estimulador de nervo periférico (ENP) é uma realidade e tem como característica evitar o contato mecânico direto da agulha com o nervo, possibilitando fácil localização do mesmo, sem ocasionar lesão.

\section{RELATD DO CASD}

Paciente de 47anos, sexo masculino, P1 (antigo ASA I), com programação cirúrgica de artroscopia do ombro direito. Conduta anestésica efetuada com bloqueio interescalênico D com ENP, seguido de anestesia geral com intubação orotraqueal. Após diversas tentativas de localização do nervo, com estímulos de $1 \mathrm{~mA}$, o paciente passou a referir parestesia sem resposta motora. Optou-se pela troca do aparelho sem retirada da agulha do local parético, com obtenção de resposta motora através de estímulo inferior a $0,15 \mathrm{~mA}$, sugerindo que a agulha estaria em contacto direto com o nervo. A agulha foi então afastada, até a aferição de resposta motora com $0,35 \mathrm{~mA}$, seguida de infusão do anestésico local sem intercorrências. A evolução no pós-operatório se deu com bloqueio efetivo, sem seqüelas.

DISCUSSÃ

Houve, neste relato de caso, exposição do paciente a complicações anestésicas graves por falha de aparelhagem, provan- do a importância do conhecimento das técnicas adequadas, da anatomia da região e da avaliação de forma rotineira dos materiais disponíveis. Na literatura não foi encontrado relato com esse tipo de intercorrência, contudo existem alguns estudos comparativos entre realização de bloqueios periféricos com ou sem o uso de estimuladores de nervo, discorrendo sobre vantagens e desvantagens de cada técnica.

REFERÊNCIAS

1. Choyce A, Chan VW, Middleton WJ, et al. What is the relationship between paresthesia and nerve stimulation for axillary brachial plexus block? Reg Anesth. Pain Med. 2001; 26(2):100-4.

2. Karaca P, Hadzic A, Yufa M, Vloka JD, et al. Painful paresthesiae are infrequent during brachial plexus localization using low-current peripheral nerve stimulation. Reg Anesth. Pain Med. 2003;28(5):380-3.

3. Sia S, Bartoli M, Lepri A, Marchini O, et al. Multiple injection axillary brachial plexus block a comparison of two methods of nerve localization-nerve stimulation versus paresthesia, Anesth Analg. 2000;91(3):647-51.

Endereço para correspondência:

Waldir Cunha Júnior

Rua Cayowáa, 560 - apto. 132 - Perdizes

São Paulo (SP) - CEP 05018-000

Tel. (+55 11) 3069-6787

E-mail:mvg@uol.com.br 